\title{
GLM-Based Analysis on Seasonal Variation of Fishery Resources in Dapeng Bay, China
}

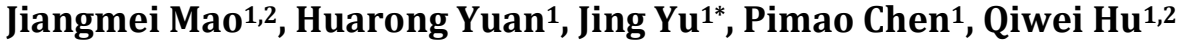 \\ ${ }^{1}$ South China Sea Fisheries Research Institute, Chinese Academy of Fishery Sciences/Key Laboratory of Fishery Ecology and En- \\ vironment, Guangdong Province/Scientific Observing and Experimental Station of South China Sea Fishery Resources and Envi- \\ ronment, Ministry of Agriculture/Key Laboratory of Marine Ranching Technology, CAFS, Guangzhou, China \\ ${ }^{2}$ College of Marine Science, Shanghai Ocean University, Shanghai, China \\ Email: *yujing@scsfri.ac.cn
}

How to cite this paper: Mao, J.M., Yuan, H.R., Yu, J., Chen, P.M. and Hu, Q.W. (2017) GLM-Based Analysis on Seasonal Variation of Fishery Resources in Dapeng Bay, China. Journal of Geoscience and Environment Protection, 5, 32-45. https://doi.org/10.4236/gep.2017.510004

Received: September 15, 2017

Accepted: October 15, 2017

Published: October 19, 2017

Copyright $\odot 2017$ by authors and Scientific Research Publishing Inc. This work is licensed under the Creative Commons Attribution International License (CC BY 4.0).

http://creativecommons.org/licenses/by/4.0/ c) (i) Open Access

\begin{abstract}
Dapeng Bay is a typical offshore fisheries area in the South China Sea (SCS). In order to understand the fishery resources, seasonal variations of species composition, dominant species composition, standardized catch per unit effort (SCPUE) and community diversity of fishery resources in Dapeng Bay, China were analyzed based on trawl survey data in spring (March) and summer (May) of 2013 as well as autumn (August) and winter (December) of 2012. Results demonstrated that there are 113 fishery species, which belong to 78 categories, 50 families, 14 catalogues, 3 classes. There are the most species in summer (61 species) and about 56 species in other seasons. In all four seasons, fish and crustacea are dominant species, and there are the fewest cephalopoda. High values of SCPUE occur in spring and autumn, reaching 5.65 and 5.33 , respectively. SCPUE is generally low in summer, ranging between 0.52 0.96 . Fish biodiversity is the highest in summer and the lowest in winter. Among biodiversity, Shannon-Wiener diversity index, Margalef diversity index and Pielou evenness index vary in the same trend. They are decreasing from summer, spring, autumn to winter successively. Therefore, there are violent seasonal variation of species composition, quantity and structure of fishery resources in Dapeng Bay. The community structure and function are highly stable in summer, but they have poor stability in autumn and winter. This research can provide scientific references for protection and sustainable use of fishery resources in typical offshore fisheries area in the SCS.
\end{abstract}

\section{Keywords}

Fishery Resources, Generalized Linear Models, Standardized Catch Per Unit Effort, Community Diversity 


\section{Introduction}

Quantity, density, distribution and community diversity of fishery resources not only reflect utilization of fishery resources, but also important contents to understand coastal ecological environment. Structure and function of fishery resources are often used as one of health evaluation indexes of marine ecosystem [1]. Abundance and composition of fishery resources are closely related with human factors and natural factors. Research has pointed out that increasing human activities will decrease marine biodiversity. Habitat degradation is one of the major factors of biodiversity reduction [2] [3]. In coral reef waters, structural changes of fishery resources are highly related with utilization intensity of resources [4]. Transformation from high-nutrient fish species to low-nutrient fish species reflects the increasing utilization intensity of fishery resources in coral reef waters. Chlorophyll a concentrations (Chl-a), biomass and species quantity of nekton are increased in artificial fish reef waters, which protect and facilitate local marine ecosystem [5] [6] [7]. In marine ecological environment, temperature can affect metabolism, ingestion, spawning and distribution of marine organism directly [8] [9] [10]. Photosynthetic pigments of phytoplankton are an index of marine primary productivity. When chlorophyll concentration is higher than $0.20 \mathrm{mg} / \mathrm{m}^{3}$, there's enough phytoplankton in the sea area for commercial fishing of certain fishery resources [11]. In addition, land runoff, monsoon and tropical cyclone bring nutritive salts to sea areas through current transmission, water mass and upwelling and increases primary productivity, thus increasing local fish stock [12] [13]. In the north of South China Sea (SCS), fish species with long life, big size and high nutrient are decreasing, while fish species with short life, small size and low nutrients are increasing [14] [15]. In the middle area of SCS, midwater fishery biocoenosis is facing with intensive catching activities in autumn and moderate catching activities in winter [16]. Marinefish lay eggs, seeking foods and migrate along a certain direction in the seawater periodically according to characteristics of life [17]. These lay a foundation for exploring the relationship between marine environment and fish abundance, and further guiding fishery production activities.

Dapeng Bay is a typical fisheries area in the coasts of SCS, with typical representativeness in the offshore area of SCS. Based on trawl survey data in Dapeng Bay from 2012-2013, CPUE was standardized by the generalized linear models (GLM) and seasonal variation on species and community diversity of local fishery resources was analyzed. Seasonal variations of fishery resources in Dapeng Bay are analyzed, aiming to provide scientific references for sustainable utilization and management of fishery resources in the coastal area of SCS.

\section{Materials and Methods}

\subsection{Research Area and Survey Station}

Dapeng Bay locates in the north of the SCS and the western Shenzhen sea area. There are $0.40 \mathrm{~km}^{2}$ of shallow sea aquiculture area and $2.54 \mathrm{~km}^{2}$ of artificial fish 
reef area. Net cage and buoyant raft hanging culture are dominant aquiculture ways. It is a typical offshore fisheries area in the SCS (Figure 1(a)) [18] [19] [20] [21]. In this study, 6trawl survey stations (S1, S2, S3, S8, S9 and S10) and 9 environment survey stations (S1, S2, S3, S4, S5, S6, S7, S8 and S9) (Figure 1(b)) were set in Dapeng Bay. Trawl surveys, sea surface temperature (SST) and Chl-a were carried out on March (spring) and May (summer) of 2013 as well as August (autumn) and December (winter) of 2012 by using the same bottom trawler. The total tonnage of the bottom trawler, main motor power, average network width and average trawl speed and average trawl duration were $63 \mathrm{t}, 99.23 \mathrm{Kw}, 2.4 \mathrm{~m}$, 2.5 sections and $0.25 \mathrm{~h}$, respectively.

\subsection{GLM-based SCPUE and Kriging Spatial Interpolation}

With reference to the method of Guan [22]. Monthly CPUE were standardized using R software and GLM. Before standardization, CPUE was logarithmized to be close to the normal distribution. The general expression of GLM model is:

$$
\text { Lg }(\text { CPUE }+c)=\text { Year }+ \text { Lon }+ \text { Lat }+ \text { Month }+ \text { SST }+ \text { Chl-a + error }
$$

where CPUE is the caught mantissa in trawl survey per hour, $\mathrm{c}$ is a constant and is determined $10 \%$ of total average number, Year is year, Lon is longitude effect, Lat is latitude effect, Month is monthly effect, SST is sea surface temperature,

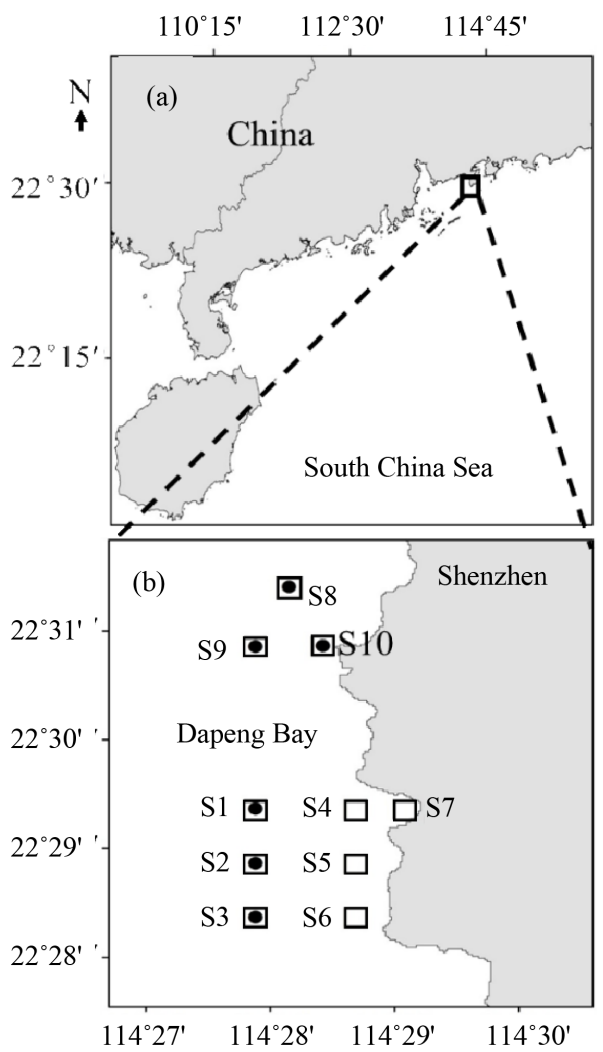

Figure 1. Research area and survey stations. $x$ axis longitude and y axis latitude $\square$ Environment survey stations • Trawl survey stations 6 trawl survey stations (S1, S2, S3, S8, S9 and S10) 9 environment survey stations (S1, S2, S3, S4, S5, S6, S7, S8 and S9). 
and Chl-a is Chlorophyll a concentration. error obeys to the normal distribution of $\mathrm{N}\left(0, \sigma^{2}\right)$.

Common Kriging interpolation of large-sized and unevenly distributed data has been accepted as the best method and is widely used in many fields. Based on spatial information of Chl-a and SST, the common Kriging method of statistical module in ArcGIS spatial interpolation was adopted for spatial interpolation of environmental survey data in Dapeng Bay in spring (March) and summer (May) of 2013 as well as autumn (August) and winter (December) of 2012 [23].

\subsection{Analytical Method}

In all survey, sample collection and analysis were accomplished according to Specification for Marine Monitoring (GB17378-2007) and Specifications for Oceanographic Survey Marine Biological Survey (GB/T12763.6-2007). Quantity and weight of caught fish species were recorded in site. Species identification and biological test were performed in laboratory. Dominant species were established according to the calculated degree of dominance [24]. Community diversity of fishery resources in trawl surveys used Margalef diversity index $(D)$, Shannon-Wiener diversity index $(H)$, and Pielou evenness index $(J)$. Formulas are:

$$
\begin{aligned}
Y & =\frac{n_{i}}{N} * f_{i}, \\
D^{\prime} & =(S-1) / \ln N, \\
H^{\prime} & =-\sum_{i=1}^{S} P_{i} \log _{2} P_{i}, \\
J^{\prime} & =H^{\prime} / \log _{2} S,
\end{aligned}
$$

where $n_{i}$ is the catch quantity of the $i^{\text {th }}$ species, $f_{i}$ is the frequency of occurrence of the $i^{\text {th }}$ species, $N$ is total number of biontin samples, $S$ is total species in bottom trawl samples, and $P_{i}$ is percentage of the $i^{\text {th }}$ species in total number of samples.

\section{Results}

\subsection{Seasonal Variation of Dominantspecies}

A total of 113 species were caught in Dapeng Bay in four seasons, which belong to 78 categories, 50 families, 14 catalogues, 3 classes. Most of them are Decapo$d a$, accounting for 35 species (30.97\%) of 10 families. Perciformes is the second dominant species, accounting for 33 species $(29.20 \%)$ of 14 families. Teuthoidea and Octopoda have the least proportions, accounting for 1 species $(0.89 \%)$ of 1 family, respectively. In all four seasons, there are the most species in summer (61 species) and fewer species in rest three seasons (56 species) (Figure 2). Fish andcrustacea are dominant species in all seasons, and cephalopodais the least species. Seasonal variation trends of species number in Dapeng Bay are basically consistent. However, species migrating into the Dapeng Bay for reproduction 


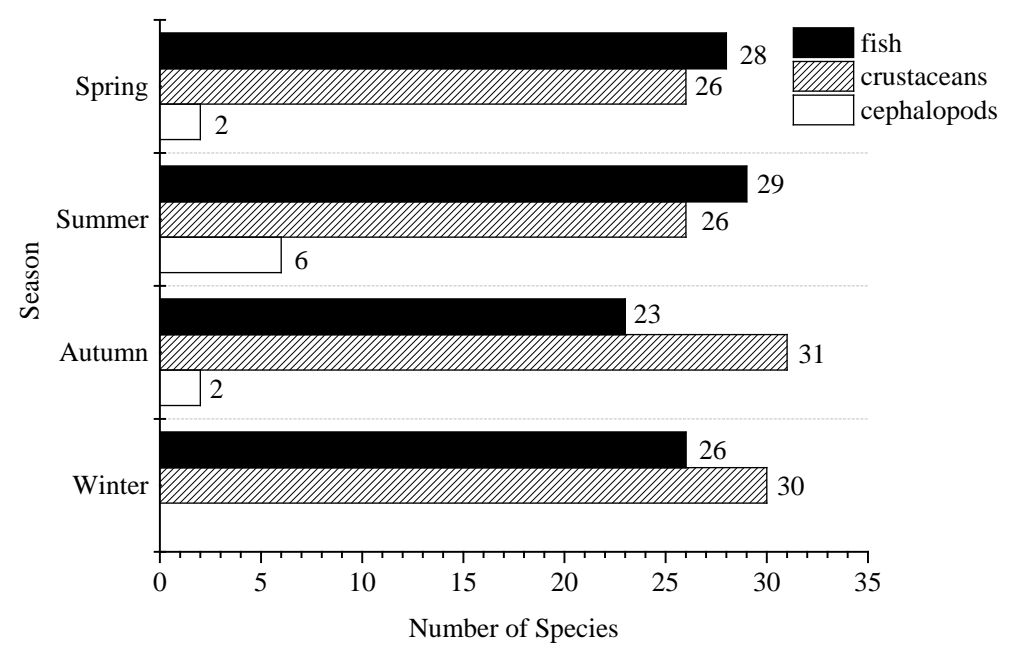

Figure 2. Seasonal variation of species number in Dapeng Bay.

and seeking foods change greatly in different seasons.

There are 29 dominant species with the dominance $\mathrm{Y}>0.02$ (Table 1). Autumn has the most dominant species (10 species), followed by summer ( 9 species) and spring (6 species). Dominant species in different seasons vary greatly, showing significant seasonal changes. Fish is the dominant species in summer, mainly including Leiognathusbrevirostris and Parargyropsedita. Crustaceais the dominant species in spring, autumn and winter. Among dominant species, Dorippefacchino occupies the absolute advantage in spring and winter $(\mathrm{Y}=0.36$ and 0.61$)$, and Oratosquillaoratoria occupies the absolute advantage in summer and autumn $(\mathrm{Y}=0.14$ and 0.47$)$.

\subsection{CPUE Standardization}

Statistical distribution of CPUE in the research area has to be determined before GLM-based standardization. The CPUE histogram shows skewed normal distribution (Figure 3(a)). Such skewed normal distribution is improved to some extent by logarithm transformation of CPUE and becomes close to symmetric distribution (Figure 3(b)). Therefore, logarithm transformation of CPUE is needed (the blank is data missing). Modelling the data with a SCPUE using GLM can improve accuracy to eliminate the effects of station, season, longitude and latitude [25]. The result of SCPUE was showed (Table 2) based on the GLM model.

\subsection{Relationship between SCPUE and Environments}

It can be seen from Figure 4 that the region with high SCPUE mainly occurs in S3 (5.65) and S9 (5.33). The corresponding SST and Chl-a are $20.59^{\circ} \mathrm{C}$ and 1.99 $\mathrm{mg} / \mathrm{m}^{3}$ as well as $30.47^{\circ} \mathrm{C}$ and $1.07 \mathrm{mg} / \mathrm{m}^{3}$, respectively. Region with low SCPUE mainly occurs in S10 (0.52) and S3 (0.79). The corresponding SST and Chl-a are $29.92^{\circ} \mathrm{C}$ and $1.76 \mathrm{mg} / \mathrm{m}^{3}$ as well as $22.84^{\circ} \mathrm{C}$ and $1.74 \mathrm{mg} / \mathrm{m}^{3}$, respectively. SCPUE distribution has obvious seasonal variations. In spring, SCPUE at S3 is high 
Table 1. Dominant species and dominant index in Dapeng Bay.

\begin{tabular}{|c|c|c|}
\hline & Fish & Crustaceans \\
\hline \multirow{10}{*}{ Spring } & Parargyropsedita & Dorippefacchino \\
\hline & 0.03 & 0.36 \\
\hline & & Portunushastatoides \\
\hline & & 0.09 \\
\hline & & Portunussanguinolentus \\
\hline & & 0.04 \\
\hline & & Eucratecrenata \\
\hline & & 0.03 \\
\hline & & Parapenaeopsistenella \\
\hline & & 0.03 \\
\hline \multirow{10}{*}{ Summer } & Leiognathusbrevirostris & Oratosquillaoratoria \\
\hline & 0.08 & 0.14 \\
\hline & Parargyropsedita & Metapenaeopsispalmensis \\
\hline & 0.06 & 0.97 \\
\hline & Lepidotrigla japonica & Parthenope validus \\
\hline & 0.05 & 0.054 \\
\hline & Sauridaundosquamis & Dorippefacchino \\
\hline & 0.04 & 0.04 \\
\hline & Apogonquadrifasciatus & \\
\hline & 0.04 & \\
\hline \multirow{16}{*}{ Autumn } & Siganusoramin & Oratosquillaoratoria \\
\hline & 0.07 & 0.47 \\
\hline & Polynemussextarius & Arcaniaheptacantha \\
\hline & 0.04 & 0.17 \\
\hline & & Parthenope validus \\
\hline & & 0.17 \\
\hline & & Hemigrapsussanguineus \\
\hline & & 0.17 \\
\hline & & Portunustrituberculatus \\
\hline & & 0.17 \\
\hline & & Charybdis bimaculata \\
\hline & & 0.17 \\
\hline & & solaris \\
\hline & & 0.17 \\
\hline & & Metapenaeopsispalmensis \\
\hline & & 0.04 \\
\hline \multirow{6}{*}{ Winter } & Polynemussextarius & Dorippefacchino \\
\hline & 0.03 & 0.61 \\
\hline & & Portunussanguinolentus \\
\hline & & 0.10 \\
\hline & & Portunushastatoides \\
\hline & & 0.07 \\
\hline
\end{tabular}

(5.65) (Figure 4(a)). Corresponding SST and Chl-a are $20.59^{\circ} \mathrm{C}$ and $1.99 \mathrm{mg} / \mathrm{m}^{3}$. In summer, SPUE is generally low (0.52 - 0.96) (Figure 4(b)). SST and Chl-a are $29.41-30.10^{\circ} \mathrm{C}$ and $1.55-3.73 \mathrm{mg} / \mathrm{m}^{3}$, respectively. In autumn (Figure $4(\mathrm{C})$ ), SCPUE at S8 and S9 are high, valuing 4.09 and 5.33. SST and Chl-a are $30.70^{\circ} \mathrm{C}$ and $1.67 \mathrm{mg} / \mathrm{m}^{3}$ as well as $30.47^{\circ} \mathrm{C}$ and $1.07 \mathrm{mg} / \mathrm{m}^{3}$, respectively. In winter, 


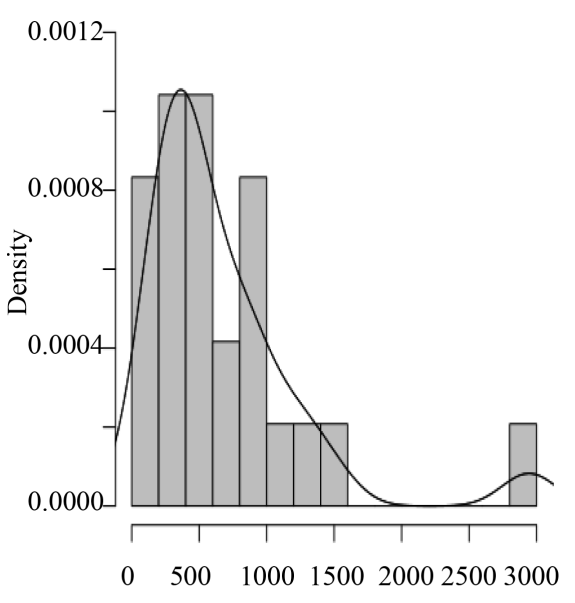

(a)

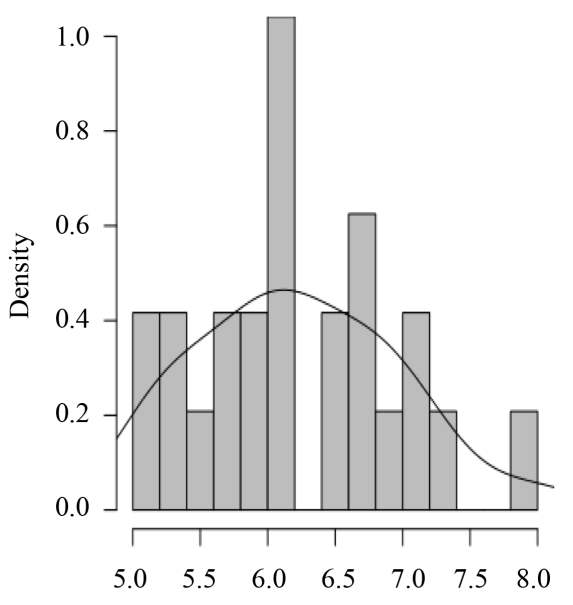

(b)

Figure 3. Density distribution of (a) CPUE and (b) lgCPUE.

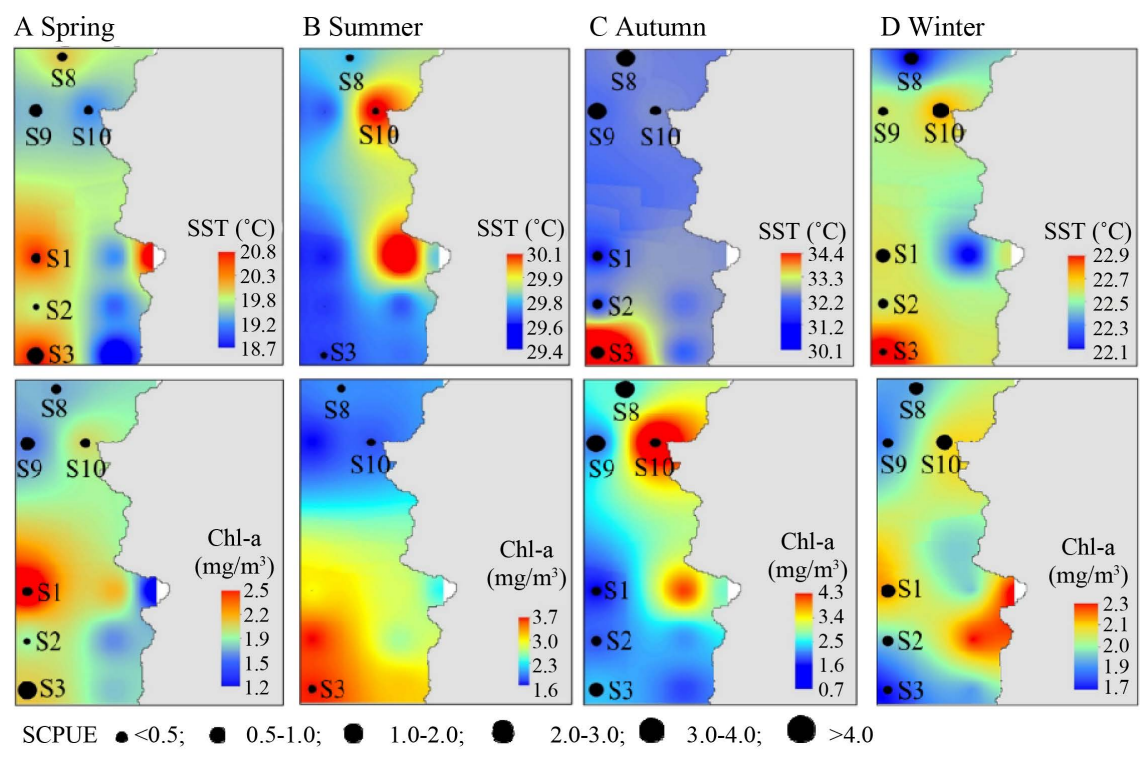

Figure 4. Relationship between standardized CPUE and SST and Chl-a.

SCPUE at S10 is high (3.51) (Figure 4(d)). SST and Chl-a are $22.65^{\circ} \mathrm{C}$ and 2.08 $\mathrm{mg} / \mathrm{m}^{3}$, respectively.

\subsection{Community Diversity of Fishery Resources}

Community diversity indexes in Dapeng Bay include Margalefdiversity index, Shannon-Wiener diversity index and Pielou evenness index, which show obvious seasonal variations (Figure 5). Margalefdiversity index ranges between 16.95 - 21.85. Shannon-Wiener diversity index ranges between 2.49 - 4.69, and Pielou evenness index ranges between $0.43-0.79$. The community diversity indexes decrease from summer, spring, autumn to winter successively. In all four seasons, there are the most abundant fishery resources in summer and the least in winter. 


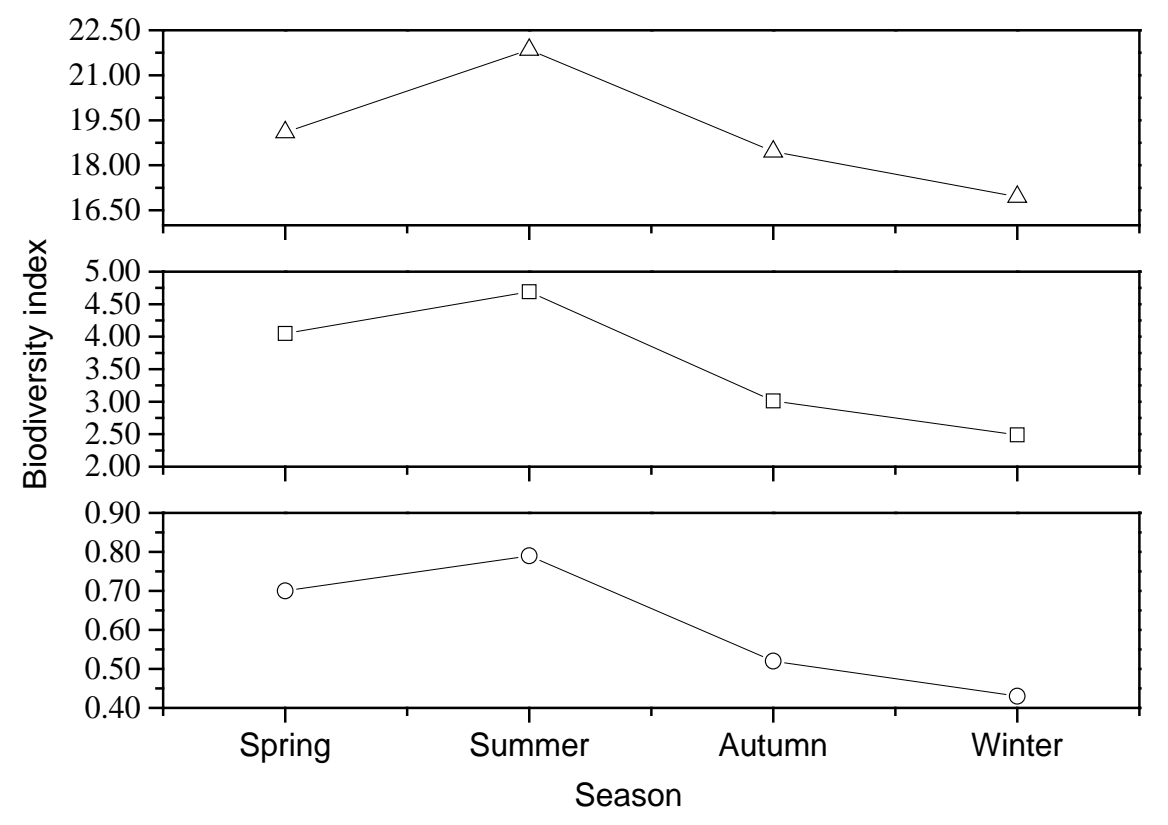

Figure 5. Seasonal variation of biodiversity index in Dapeng Bay.

\section{Discussion}

\subsection{Seasonal Variation of Fishery Resources in Dapeng Bay}

Dapeng Bay possesses abundant fishery resources. There are the most fishery species in summer and relatively fewer in rest three seasons, conforming to the trawl survey of $\mathrm{Xu}$ et al. [26] on seasonal variation of fishery resources in southwestern continental shelf of Nansha Islands. There are great seasonal differences in species composition in Dapeng Bay. Spawning, seeking food and overwintering migration of fishery species which are induced by changes of sea surface temperature and bait will cause seasonal changes of species composition and biomass, thus influencing changes of the fish stockstructure [27].

Fish is the dominant species in summer in Dapeng Bay. Fish species such asParargyropsedita has big size, long life and slow growth. They pertain to $\mathrm{k}$ selective type, but have low degree of dominance. In spring, autumn and winter, degree of dominance of big fish is relatively low. Dominant species include Polynemussextarius, Parachaeturichthyspolynema, etc. Crustaceaoccupies the absolute advantage. Dominant species such as Oratosquillaoratoria and Dorippefacchino have high degree of dominance. These small biological species have short life and quick growth. They belong to the r selective type [14] [15]. Since fishery catching activities mainly focus on fish species with high economic value and high quality, the related dominant species are few and the degree of dominance is relatively low. The catching intensity of biological species with fast growth and low economic value is low, thus resulting in more dominant species and high degree of dominance. These are consistent with $\mathrm{Wu}$ et al. who pointed that crustacean resources are increasing in relative to the reduction of fish resources [28]. It will cost a long time to recover once high-quality fishery resources are 
damaged [29]. Therefore, the dominant species of $\mathrm{k}$ selective species are replaced by $r$ selective species during the summer-autumn transition. Fish species with long life, big size and high nutrient are reducing, while crustacean with short life, small size and low nutrient is increasing.

Margalef diversity index, Shannon-Wiener diversity index and Pielou evenness index show basically same seasonal variations. They achieve the highest in summer, followed by spring, autumn and winter successively. The highest community diversity is achieved in summer, indicating that there are the most abundant fishery resources in summer and the community structure in summer is the closest to the ideal state [30] [31]. These are in accordance with survey results: the highest number of species and dominant species is achieved in summer, and the lowest community diversity in winter is in accordance with few species and few dominant species in winter. Moreover, the fishery community structure in the study area is highly stable in summer, but presents poor stability in autumn and winter. This might be because summer is the fishing off season and has low catching intensity. SPUE is relatively low and fishery resources can be supplemented and updated. The catching intensity increases in autumn after the fishing off season. SCPUE increases and fishery resources are destroyed seriously. Biocenosis loses recovery ability and integrity, and the ecosystem stability declines. The proportion of dominant species with small size and low nutrient ( $\mathrm{r}$ selective species) increases, while the proportion of dominant species with large size and high nutrient (k selective type) decreases [32] [33]. The increasing catching intensity in autumn intensifies degeneration of fishery resources to some extent, resulting in single community structure. Excessive catching will cause species degradation and depletion. $\mathrm{K}$ selective type is replaced by $r$ selective type as the dominant species [34].

\subsection{Relationship between Biomass of Fishery Resources and Environment}

SST is one of the most important environmental factors that influence fishery resources. It is one of evaluation indexes of physical changes, including ocean current, water mass, tidal, fishing ground and primary productivity [35]. In Dapeng Bay, the highest SCPUE in spring occurs at S3 station where the SST is $20.59^{\circ} \mathrm{C}$ and the lowest is in $\mathrm{S} 2$ station where the SST is $19.86^{\circ} \mathrm{C}$, indicating that distribution of fishery resources is very sensitive to temperature changes. Chen et al. [17] pointed out that only few centigrades of temperature changes are great changes. Some fish species even can perceive tiny SST changes of $0.1^{\circ} \mathrm{C}$ [36]. In summer, SCPUE data at S1, S2 and S10 station are missing (Figure 4(B)). This might be caused by the spatial separation trend of fish, crustacea and cephalopoda, that is, ecological niche differentiation. Summer is the spawning and reproduction period of most fish species, so their distribution areas mainly concentrate in spawning or maturing fields. However, crustacea and cephalopoda have no significant aggregation or different aggregation waters [37]. High SCPUE values occur at S9 and S8 station in autumn, and at S10 station in winter. 
This might be because $\mathrm{S} 8, \mathrm{~S} 9$ and $\mathrm{S} 10$ station are aquaculture regions which provide abundant bait sources and good growth environment for fishery industry. Therefore, SCPUE at these stations are higher than those at S1, S2 and S3 station.

Fishery resource distribution based on Chl-a is related with marine food chain mechanism. The abundant phytoplankton resources attract a lot of zooplankter which live on them, thus further enriching fishery resources which live on the zooplankter. In this study, SCPUE is high when Chl-a is low in spring (1.99 $\left.\mathrm{mg} / \mathrm{m}^{3}\right)$ and autumn $\left(1.07 \mathrm{mg} / \mathrm{m}^{3}\right)$. This reflects the "low Chl-a and high fishery resources" to some extent [38]. In summer, SCPUE is generally low, which is related with the low catching intensity due to the fishing off season [39]. However, fishery resources are supplemented and updated to some extent after the fishing off season and catching intensity increases, thus resulting in high SCPUE in autumn [40].

\subsection{Suggestions on Protection and Sustainable Utilization of Fishery Resources}

Dapeng Bay is in the northwest waters of the SCS with low latitude. Characteristics of fishery resource structure are mainly caused by reduction of fishery organism and frequent species replacement caused by excessive catching as well as poor community stability. Therefore, it is necessary to change the traditional exhausting catching pattern and control and reduce catching intensity strictly. It shall reduce catching activities of fishing ships, determine catching intensity and maximum proportion of larva, and use the smallest meshing size [41] to protect fishery larva. Targeted catching according to time shall be adopted. For example, there are $\mathrm{k}$ selective type and $\mathrm{r}$ selective type of fishery resources in summer Dapeng Bay, but $r$ selective type of fishery resources is mainly in rest three seasons. It shall use mainly trawl in summer, but shrimp trawl with crossyard and cage pot shall be adopted in autumn and winter. These can increase catching efficiency and protect species degradation better, thus making fishery resources recovered and supplemented. In addition, it has to prolong fishing off season and expand species of fishing prohibition. Generally, the fishing off season in summer is short and fishery resources recovery is time-consuming. Prolonging the fishing off season and expanding species of fishing prohibition appropriately give adequate time for fishery resources recovery, supplement more species and can reduce the degree of resources damage. Moreover, it is suggested to reproducing and releasing of species at different ecological niche. Full considerations shall be given to blank ecological niches caused by species depletion and spatial-temporal heterogeneity of fishery biocenosis [42]. The one-way species releasing shall change to reproduction and releasing based on ecological balance, aiming to facilitate sustainable development of fishery resources.

\section{Conclusion}

In this study, seasonal variations of fishery resources in typical offshore fisheries 
areas in SCS are analyzed based on Dapeng Bay, China. SCPUE of fishery resources in Dapeng Bay is low in summer, indicating that the fishing off policy in summer can protect fishery resources to some extent. The community diversity is higher in summer and low in winter. The energy transfer efficiency between different nutrient levels in Dapeng bay in spring and summer is relatively close, indicating that the ecosystem is relatively table. $\mathrm{K}$ selective type is the dominant species in summer and $r$ selective type is the dominant species in autumn. This reflects that catching intensity can influence regional resource structure. The catching intensity in autumn is higher than that in summer, so $r$ selective type will replace the $\mathrm{k}$ selective type as the dominant species. Further investigation will be conducted on Dapeng Bay, providing scientific references for protection and sustainable use of fishery resources in typical offshore fisheries area in the SCS.

\section{Acknowledgements}

This work was supported by National Key Technology Support Program (No. 2012BAD18B01, 2012BAD18B02) and the Science and Technology Project of Shenzhen of China (No.JSGG20141015154342147, JCYJ20160331141759795).

\section{References}

[1] Shi, Y.R., Chao, M., Quan, W.M., Tang, F.H., Shen, X.Q. and Huang, H.J. (2011) Spatial Variation in Fish Community of Yangtze River Estuary in Spring. Journal of Fishery Science of China, 18, 1141-1151. https://doi.org/10.3724/SP.J.1118.2011.01141

[2] Hurd, L.E., Sousa, R.G.C., Siqueira-Souza, F.K., Cooper, G.J., Kahn, J.R. and Freitas, C.E.S. (2016) Amazon Floodplain Fish Communities: Habitat Connectivity and Conservation in a Rapidly Deteriorating Environment. Biological Conservation, 195, 118-127. https://doi.org/10.1016/j.biocon.2016.01.005

[3] Mccauley, D.J., Pinsky, M.L., Palumbi, S.R., Estes, J.A., Joyce, F.H. and Warner, R.R. (2015) Marine Defaunation: Animal Loss in the Global Ocean. Science, 347, Article ID: 1255641 . https://doi.org/10.1126/science.1255641

[4] Zgliczynski, B.J. and Sandin, S.A. (2017) Size-Structural Shifts Reveal Intensity of Exploitation in Coral Reef Fisheries. Ecological Indicators, 73, 411-421. https://doi.org/10.1016/j.ecolind.2016.09.045

[5] Yu, J., Chen, P.M., Tang, D.L. and Qin, C.X. (2015) Ecological Effects of Artificial Reefs in Daya Bay of China Observed from Satellite and in situ Measurements. Advances in Space Research, 55, 2315-2324. https://doi.org/10.1016/j.asr.2015.02.001

[6] Yu, J., Chen, P.M. and Zhao, M. (2014) Satellite Remote Sensing Assessment of Ecological Effects of Artificial Reefs in Daya Bay. International Conference on Remote Sensing and Smart City, Shenzhen 27-28 July 2014. https://doi.org/10.2495/RSSC140321

[7] Becker, A., Taylor, M.D. and Lowry, M.B. (2016) Monitoring of Reef Associated and Pelagic Fish Communities on Australia's First Purpose Built Offshore Artificial Reef. Journal of Marine Science, 74, 277-285. https://doi.org/10.1093/icesjms/fsw133

[8] Gordoa, A., Maso, M. and Voges, L.(2000) Chapter 10 Satellites and Fisheries: The 
Namibian Hake, A Case Study. Elsevier Oceanography Series, 63, 193-205. https://doi.org/10.1016/S0422-9894(00)80011-2

[9] Sund, P.N., Blackburn, M. and Williams, F. (1981) Tuna and Their Environment in the Pacific Ocean: A Review. Oceanography and Marine Biology Annual Review, 19, 443-512.

[10] Laevastu, T. and Rosa, H. (1963) Distribution and Relative Abundance of Tunas in Relation to Their Environment. FAO Fisheries Report, 6, 1835-1851.

[11] Gower, J.F.R. (1986) Opportunities and Problems in Satellite Measurements of the Sea. Report of SCOR Working Group 70. UNESCO Technical Papers in Marine Science, 46, 70 .

[12] Qiu, Y.S., Lin, Z.J. and Wang, Y.Z. (2010) Responses of Fish Production to Fishing and Climate Variability in the Northern South China Sea. Progress in Oceanography, 85, 197-212.

[13] Qiu, Y.S., Wang, Y.Z. and Chen, Z.Z. (2008) Runoff- and Monsoon-Driven Variability of Fish Production in East China Seas. Estuarine Coastal \& Shelf Science, 77, 23-34.

[14] Wang, X.H., Qiu, Y.S., Du, F.Y., Ling, Z.J., Sun, D.R. and Huang, S.L. (2011) Spatio-Temporal Variability of Fish Diversity and Dominant Species in the Beibu Gulf. Journal of Fishery Science of China, 18, 427-436. https://doi.org/10.3724/SP.J.1118.2011.00427

[15] Wang, X.H., Qiu, Y.S., Du, F.Y., Ling, Z.J., Sun, D.R. and Huang, S.L. (2012) Dynamics of Demersal Fish Species Diversity and Biomass of Dominant Species in Antumn in the Beibu Gulf, Northwestern South China Sea. Acta Ecologica Sinica, 32, 333-342. https://doi.org/10.5846/stxb201011291700

[16] Xu, Y.W., Jiang, Y.E., Fan, J.T., Kong, X.L., Zhang, K. and Chen, Z.Z. (2016) Preliminary Study on Community Structure of Mesopelagic Species in the Central South Sea during Antumn and Winter. South China Fisheries Science, 12, 49-56.

[17] Chen, X.J. (2014) Fishery Resources Biology and Fishing. Maritime Press.

[18] Yu, J., Zhao, M., Hu, Q.W. and Chen, P.M. (2017) Ecosystem Health Assessment of the Egong Bay Fisheries Area in Shenzhen Based on Index of Biological Integrity of Fish. Journal of Southern Agriculture, 48, 524-531.

[19] Chen, M.X., Li, H.Y., Li, G., Zheng, T.L., Jiao, K. and Han, Y.S. (2010) The Study on the Diversity and Distribution of Vibrios and the Correlation between Them and Their Ambient Environmental Factors in Shenzhen Coastal Waters. Acta Oceanologica Sinica, 32, 117-126.

[20] Zhao, M., Yu, J., Chen, P.M. and Feng, X. (2016) Ecosystem Health Assessment of the Egong Bay Fisheries Area in Shenzhen. Journal of Southern Agriculture, 47, 1025-1031.

[21] Zhao, M., Yu, J., Chen, P.M., Feng, X. and Nie, Y.K. (2015) Research Advances of Assessment of Bay Ecosystem Health. Journal of Anhui Agriculture, 43, 8-11.

[22] Guan, W.J., Tian, S.Q., Wang, X.F., Zhu, J.F. and Chen, X.J. (2014) A Review of Methods and Model Selection for Standardizing CPUE. Journal of Fishery Science of China, 21, 852-862.

[23] Yu, X.Q. and Ma, A.H. (2013) The Spatial Interpolation of Missing Remoting Sensing Data in Sea Surface Chlorophyll-A Using Kriging. Bulletin of Surveying and Mapping, 12, 47-50.

[24] Ding, Y.Q. (1980) Principles of Mathematical Ecology of Insect Populations. Science Press. 
[25] John, H.H., John, R.W. and Ian, J.S. (2010) Analysis of Fishery-Independent Hook and Line-Based Data for Use in the Stock Assessment of Bocaccio Rockfish ( $\mathrm{Se}$ bastes paucispinis). Fisheries Research, 106, 298-309.

[26] Xu, Y.W., Chen, Z.Z., Fan, J.T. and Zhang, J. (2015) Composition and Biodivisity of Cathes by Bottom Trawl Fishery in Southwestern Continent Shelf of Nansha Area. South China Fisheries Science, 11, 76-81.

[27] Shan, X.J., Sun, P.F., Jin, X.S. and Dai, F.Q. (2013) Seasonal Variations of Fishery Resource Structure in the Section of the Southern Yellow Sea. Journal of Fisheries of China, 37, 425-435.

[28] Wu, Q., Wang, J., Li, Z.Y., Chen, R.S., Sun, J.Q. and Jin, X.S. (2012) Spatial Variation of Crustacean Community Structure in Yellow Sea and Bohai Sea in Spring. Journal of Siageries of China, 36, 1685-1693.

https://doi.org/10.3724/SP.J.1231.2012.28005

[29] Zhang, X.Y., Liu, C., Nepal, S., Yang, C. and Dou, W. (2014) A Hybrid Approach for Scalable Sub-Tree Anonymization over Big Data Using MapReduce on Cloud. Journal of Computer and System Sciences, 80, 1008-1020.

[30] Li, Z.S. (2012) Studies on the Community Characteristics and Size Spectra of Zooplankton in the Yellow River Estuary and Its Adjacent Waters in Spring. Ocean University of China.

[31] Zuo, T., Wang, J., Jin, X.S., Li, Z.Y. and Tang, Q.S. (2008) Biomass Size Spectra of Net Plankton in the Adjacent Area near the Yangtze River Estuary in Spring. Acta Ecologica Sinica, 28, 1174-1182.

[32] Finlay, K., Beisner, B.E., Patoine, A. and Pinelalloul, B. (2007) Regional Ecosystem Variability Drives the Relative Importance of Bottom-Up and Top-Down Factors for Zooplankton Size Spectra. Canadian Journal of Fisheries \& Aquatic Sciences, 64, 516-529. https://doi.org/10.1139/f07-028

[33] Zhou, L.B., Tan, Y.H., Huang, L.M. and Lian, X.P. (2010) The Advances in the Aquatic Particle/Biomass Size Spectra Study. Acta Ecologic Sinica, 30, 3319-3333.

[34] Li, J.S., Li, S.F., Ren, Y.P. and Chen, J.H. (2004) Seasonal Varity of Fishery Biology Community Structure in Fishing Ground of the Yangtze Estuary. Journal of Fishery Science of China, 11, 432-439.

[35] Yan, M., Zhang, H., Fan, W., Jin, S.F. and Yang, S.L. (2015) Spatial-Temporal CPUE Profiles of the Albacore Tuna (Thunnusalalunga) and Their Relationships to Marine Environmental Factors in the South Pacific Ocean. Chinese Journal of Ecology, 34, 3191-3197.

[36] Victor, K. (2013) Fisheries Application of Remoting Sensing: An Overview. Fisheries Research, 148, 124-136.

[37] Liu, Y. and Cheng, J.H. (2015) Spato-Temporal Relationships among Three Groups of Fisheries Caught in Bottom Trawl Survey in the East China Sea. Acta Ecologica Sinica, 35, 3403-3410.

[38] Yu, J., Hu, Q.W., Li, C.H., Zhang, P. and Mao, J.M. (2017) Relationship between the Symplectoteuthis oualaniensis Resources and Environmental Factors in the $\mathrm{Xi}$ sha-Zhongsha Waters in Spring. Acta Oceanologica Sinica, 39, 62-73.

[39] Yuan, H.R., Chen, P.M., Qin, C.X, Li, X.G., Zhou, Y.B., Feng, X., Yu, J., Shu, L.M., Tang, C.Z. and Tong, F. (2017) Seasonal Variation of Fish Community Structure in Zhelin Bay, the South China Sea. South China Fisheries Science, 13, 26-35.

[40] Yu, J., Hu, Q.W., Yuan, H.R., Tong, F., Chen, P.M. and Mao, J.M. (2017) Effects Assessment of Summer Fishing Moratorium in Daya Bay in the Northern South 
China Sea. Journal of Geoscience and Environment Protection, 5, 96-108. https://doi.org/10.4236/gep.2017.57010

[41] Lin, L.S., Cheng, J.Y. and Ling, J.Z. (2007) Analysis on Recent Status of the Bottom Trawl Fishery Resources in the East China Sean Region. Marine Fisheries, 29.

[42] Li, T., Zhang, X.M., Zhang, P.D. and Huang, G.Q. (2011) Seasonal Variation on Community Structure of Fishery Resources in the Coastal Waters of Southern Shandong Peninsular. Periodical of Ocean University of China, 41, 41-50. 